\title{
Factors affecting TCE reduction by ZVI
}

\author{
Yanjiao Gao ${ }^{a}$, Rui Liu ${ }^{b}$, Xin Zhang $^{c}$,Jing Xiao ${ }^{d}$ \\ College of Civil Engineering and Architecture, Liaoning University of Technology, 121001 Jinzhou, \\ China \\ ayanjiaogao@163.com, ${ }^{\mathrm{b}} 407687300 @ q q . c o m,{ }^{\mathrm{c}} 511172841 @ q q . c o m,{ }^{\mathrm{d}}$ mdifferent@126.com
}

Keywords: Zero valent iron; Trichloroethylene; Optimum experimental conditions

\begin{abstract}
Zero valent iron $(\mathrm{Fe}(0))$ was used to reduce trichloroethylene (TCE).Some influence factors of TCE removal including $\mathrm{Fe}(0)$ purity, $\mathrm{Fe}(0)$ size, $\mathrm{Fe}(0)$ quality, solution $\mathrm{pH}$, reaction temperature, oscillation rate and initial concentration of TCE were investigated in the batch experiments. The optimum experimental conditions were determined as: $\mathrm{Fe}(0)$ purity of $92 \%, \mathrm{Fe}(0)$ size of 30 mesh, $\mathrm{Fe}(0)$ quality of $30 \mathrm{mg} / \mathrm{L}$, solution initial $\mathrm{pH}$ of 6.0 and reaction temperature of $25^{\circ} \mathrm{C}$. Oscillation rate and initial concentration of TCE had little effects on TCE removal. The 5-day TCE removal rate was $90.4 \%$ under the optimum conditions.
\end{abstract}

\section{Introduction}

The industrial solvent trichloroethylene (TCE) is among the most widespread chlorinated compounds found in groundwater contamination [1]. High levels of TCE is considered a likely human carcinogen ${ }^{[2]}$. The technology chosen for remediation is typically pump-and-treat. Although pump-and-treat can be effective in controlling plume migration, in-situ treatment approaches are required to better remediate and reduce risk at chlorinated solvent contamination sites. The typical technology used for TCE removal is in-situ permeable reactive walls. The main advantage of a reactive barrier is the passive nature of the treatment. Reactive barriers containing iron metals are currently being developed for in situ treatment technology ${ }^{[3]}$. In 1981, Sweeny utilized iron powders to degrade various hydrocarbons, such as trichloroethylene ${ }^{[4]}$.In 1994 Gillham and Matheson used $(\mathrm{Fe} 0)$ for treating contaminated groundwater in-situ, demonstrating the identification of $(\mathrm{Fe} 0)$ as a remediation constituent ${ }^{[5]}$. A use of $(\mathrm{Fe} 0)$ as reactive medium for TCE treatment is one of the most promising techniques because the iron metal is of low-cost, is easy-to-obtain, and has good effectiveness and ability of degrading contaminants. In addition, iron waste particles from industrial filings can be used as a zero-valent iron. Although significant progress has been made, much need to be done for studying various mechanisms of TCE removal by $(\mathrm{Fe} 0)$. In this paper some batch tests were performed to examine the application of $(\mathrm{Fe} 0)$ for TCE removal. The optimum parameters were indentified.

\section{Materials and methods}

The Fe(0) filings (97\% of purity, 30 mesh; 85\% of purity, 30 mesh ; 92\% of purity, 30 and 50 mesh) were obtained from iron processing factory. Trichloroethylene $\left(\mathrm{C}_{2} \mathrm{HCl}_{3}\right)$, sodium hydroxide $(\mathrm{NaOH})$ and hydrochloric acid $(\mathrm{HCl})$ were purchased from chemical reagent store. All chemicals used were of analytical reagent grade.

Batch experiments were performed using 300-mL glass conical flasks containing a certain quality of $\mathrm{Fe}(0)$ and a certain concentration of TCE solution. The solution $\mathrm{pH}$ was adjusted by the addition of sodium hydroxide and hydrochloric acid. The flasks were sealed with rubber plugs and aluminum covers. The solutions were shaken in oscillation boxes at a certain rotation speed and temperature the experiment required. Every five flasks with the same reaction conditions were divided into a group, and one flask was taken out from box every one day to be measured concentration of trichloroethylene using gas chromatograph. The $\mathrm{pH}$ was measured by a $\mathrm{pH}$ meter. 


\section{Results and discussion}

\subsection{Effect of $\mathrm{Fe}(0)$ purity}

Figure 1 shows the relationship between reaction time and TCE removal rate under different solution $\mathrm{pH}$. With the increase of reaction time removal rate of TCE all increased by different purity of $\mathrm{Fe}(0)$. After 5 day, TCE removal rate of $\mathrm{Fe}(0)$ purity of $97 \%, 92 \%$ and $85 \%$ was $82.4 \%, 73.7 \%$ and $65.4 \%$ respectively. TCE removal rate of $\mathrm{Fe}(0)$ purity of $97 \%$ was the highest, reached 85.2\%.The higher purity but higher were removal rate. High purity of $\mathrm{Fe}(0)$ could offer more effective reaction medium and more closely contact with the TCE solution. Therefore, reactions between $\mathrm{Fe}(0)$ and TCE were more strongly and the better effects on removing TCE were acquired The higher the $\mathrm{Fe}(0)$ purity was, the more expensive the $\mathrm{Fe}(0)$ was. $\mathrm{Fe}(0)$ purity of $92 \%$ was the best for this experiment.

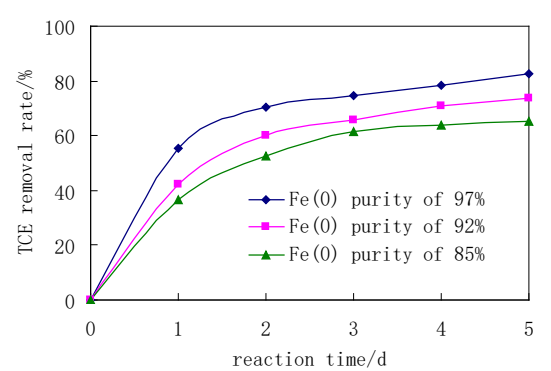

Fig. $1 \mathrm{Fe}(0)$ purity andTCE removal

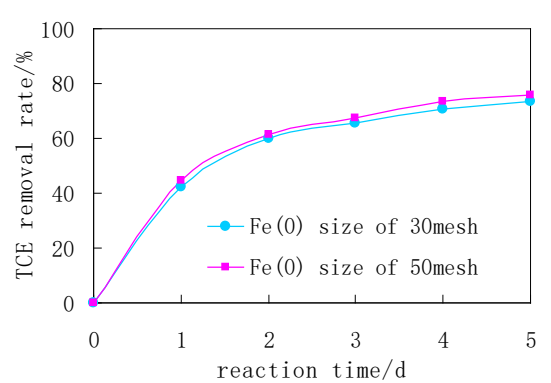

Fig. 2 Fe(0) size and TCE removal

\subsection{Effect of $\mathrm{Fe}(0)$ size}

Figure 2 shows the relationship between reaction time and TCE removal rate under different size of $\mathrm{Fe}(0)$. After 5 day, TCE removal rate of $\mathrm{Fe}(0)$ size of 50 mesh was $75.8 \%$ higher than that of size of 50 mesh 2.1 percentage points. The bigger the $\mathrm{Fe}(0)$ particle size was, the higher the TCE removal rate was. The reductive dechlorination reaction of chlorinated hydrocarbons in water of iron system was typical of the solid-liquid mass transfer reaction, the reaction was carried out mainly depending on the iron surface.Big Mesh of $\mathrm{Fe}(0)$ with small particle size and large specific surface area could effectively collide with TCE.

\subsection{Effect of $\mathrm{Fe}(0)$ quality}

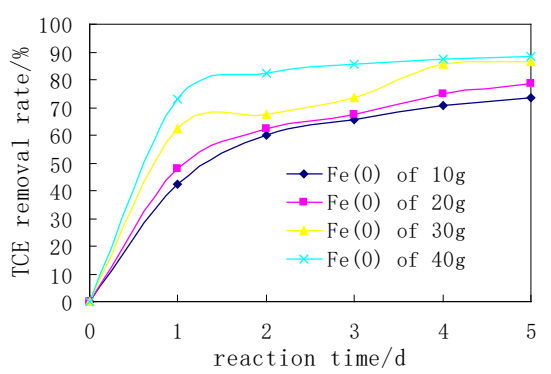

Fig. $3 \mathrm{Fe}(0)$ quality and TCE removal

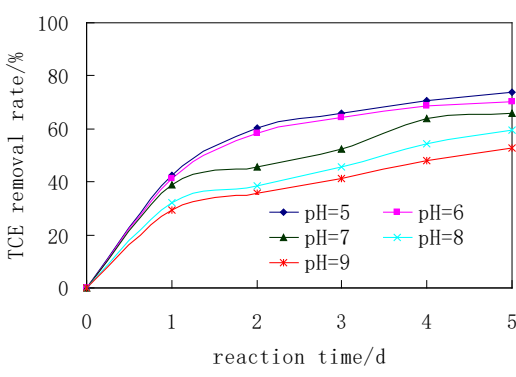

Fig. 4 solution $\mathrm{pH}$ and TCE removal

Figure 3 shows the relationship between reaction time and TCE removal rate under different quality of $\mathrm{Fe}(0)$. With the increase of reaction time removal rate of TCE all increased under different quality of $\mathrm{Fe}(0)$. After 5 day, TCE removal rate of $\mathrm{Fe}(0)$ quality of $10 \mathrm{~g}, 20 \mathrm{~g}, 30 \mathrm{~g}$ and $40 \mathrm{~g}$ was $73.7 \%, 78.4 \%, 86.4 \%$ and $88.2 \%$ respectively. TCE removal rate of $\mathrm{Fe}(0)$ quality of $40 \mathrm{~g}$ was the highest, reached $88.2 \%$.The higher quality but higher was removal rate. More dosage of $\mathrm{Fe}(0)$ had more surface area in reductive dechlorination reactions of iron and had more chances to reduce TCE. In this experiment, the removal rate of TCE by $40 \mathrm{~g} \mathrm{Fe}(0)$ was higher than that of TCE by $30 \mathrm{~g}$ $\mathrm{Fe}(0)$ only $1.6 \%$. When the $\mathrm{Fe}(0)$ quality increased to critical value of $30 \mathrm{~g}$, the reaction sites were so excessive that brought $\mathrm{Fe}(0)$ into good contact with the TCE.

\subsection{Effect of solution $\mathrm{pH}$}

Figure 4 shows the relationship between reaction time and TCE removal rate under different solution $\mathrm{pH}$. TCE removal rate of solution $\mathrm{pH} 5$ was the highest, reached $73.7 \%$. In this 
experimental when $\mathrm{pH}$ was $5 \sim 6$,TCE removal rate could reach $70 \%$ above which illustrated the acidic environment was favorable to TCE removal. Reducing dechlorination of chlorinated hydrocarbons by $\mathrm{Fe}(0)$ was the process of oxidized dissolution of metal ions. The reaction equation was following.

$$
\mathrm{Fe}^{0}+\mathrm{RCl}+\mathrm{H}^{+} \rightarrow \mathrm{Fe}^{2+}+\mathrm{RH}+\mathrm{Cl}^{-}
$$

In this dechlorination reaction, if hydrogen ion concentration increased acidic conditions caused the increase of reaction rate. With hydrogen ion concentration decreased alkaline conditions caused the surface of $\mathrm{Fe}(0)$ forming iron deposit such as Ferrous hydroxide $\left(\mathrm{Fe}(\mathrm{OH})_{2}\right)$, ferric hydroxide $\left(\mathrm{Fe}(\mathrm{OH})_{3}\right)$ and iron carbonate $\left(\mathrm{FeCO}_{3}\right)$. These deposit attached on the surface of $\mathrm{Fe}(0)$ particles formed a protective layer and hindered the further reaction of $\mathrm{Fe}(0)$ with TCE. Therefore the $\mathrm{pH}$ value increased, the removal effect declined.

\subsection{Effect of solution reaction temperature}

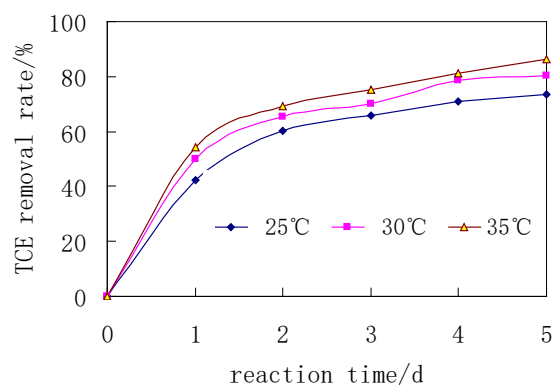

Fig. 5 temperature and TCE removal

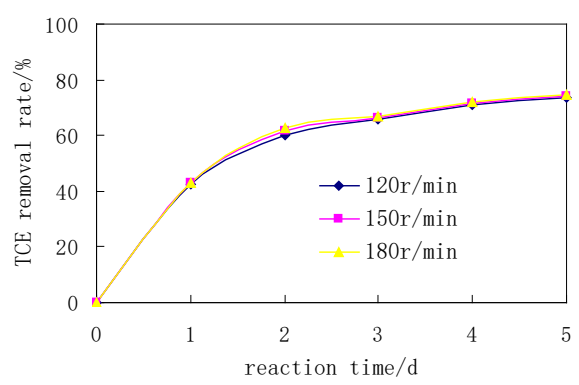

Fig. 6 oscillation rate and TCE removal

Figure 5 shows the relationship between reaction time and TCE removal rate under different reaction temperature. With the increase of reaction time removal rate of TCE all increased under different reaction temperature. After 5 day, TCE removal rate of $25^{\circ} \mathrm{C}, 30^{\circ} \mathrm{C}$ and $35^{\circ} \mathrm{C}$ was $73.7 \%$, $80.3 \%, 86.2 \%$ respectively. TCE removal rate of $35^{\circ} \mathrm{C}$ was the highest, reached $86.2 \%$.The higher temperature but higher was removal rate. With temperature increasing the mass transfer rate between the reaction media accelerated and chemical reaction rate accelerated. Considering the general laboratory room temperature was $25^{\circ} \mathrm{C}$ optimal temperature of this experiment was determines at $25^{\circ} \mathrm{C}$.

\subsection{Effect of oscillation rate}

Figure 6 shows the relationship between reaction time and TCE removal rate under different oscillation rate. With the increase of reaction time removal rate of TCE all increased under different oscillation rate. After 5 day, TCE removal rate of oscillation rate $120 \mathrm{r} / \mathrm{min}, 150 \mathrm{r} / \mathrm{min}$ and $180 \mathrm{r} / \mathrm{min}$ was $73.7 \%, 74 \%$ and $74.5 \%$ respectively. With the increase of oscillation rate, the removal rate of TCE increased slightly, which had little effect on the experiment. $\mathrm{Fe}(0)$ had characteristics of very small size and large surface area, and can be evenly distributed in the solution on the condition of $120 \mathrm{r} / \mathrm{min}$. Oscillation rate of $120 \mathrm{r} / \mathrm{min}$ was the best for this experiment.

\subsection{Effect of initial TCE concentration}

Figure 7 shows the relationship between reaction time and TCE removal rate under different initial TCE concentration. With the increase of reaction time removal rate of TCE all increased under different initial TCE concentration. After 5 day, TCE removal rate of initial TCE concentration $150 \mathrm{mg} / \mathrm{L}$ was the highest, reached77.6\%. With the increase of initial TCE concentration, the removal rate of TCE increased slightly, which had little effect on the experiment. Dechlorination reaction of Granular iron and chlorinated hydrocarbons dechlorination was the surface reaction which includes mass transfer, adsorption, electron transfer and desorption processes. These reaction processed was not be changed by increase of initial concentration of TCE . 


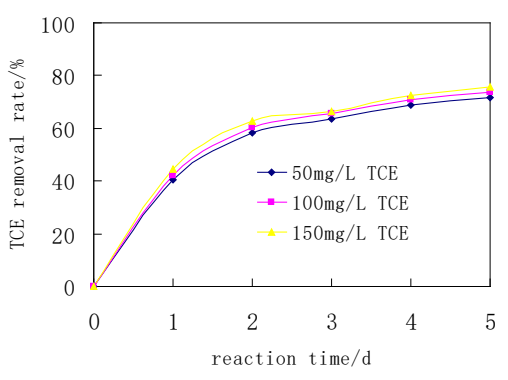

Fig.7 TCE concentration and TCE removal

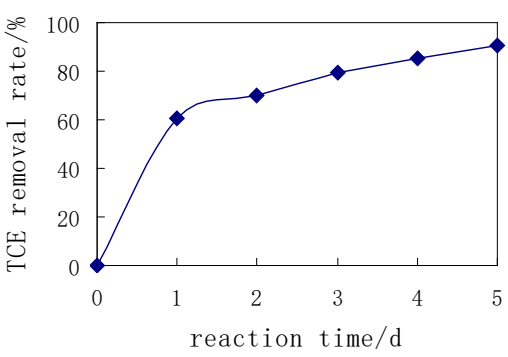

Fig.8 TCE removal at optimal conditions

\subsection{The optimum conditions of the experiments}

The optimum conditions for the batch experiments were as follow: $\mathrm{Fe}(0)$ purity of $92 \%$, $\mathrm{Fe}(0)$ size of 30 mesh, $\mathrm{Fe}(0)$ quality of $30 \mathrm{mg} / \mathrm{L}, \mathrm{pH}=6.0$, temperature of 25 ôscilhation rate of $120 \mathrm{r} / \mathrm{min}$.The experimental results under optimum conditions is shown in Fig.8. The 5- day TCE removal rate of was $90.4 \%$, which testified that using $\mathrm{Fe}(0)$ to dispose TCE was feasible, and could achieve good results.

\section{Conclusions}

The main influence factors of $\mathrm{Fe}(0) \quad$ reduction of TCE were $\mathrm{Fe}(0)$ purity, $\mathrm{Fe}(0)$ size, ZVI Fe(0) quality, solution $\mathrm{pH}$, reaction temperature. Oscillation rate and initial concentration of TCE had little effects on TCE removal.The optimum conditions for the batch experiments were as follow: $\mathrm{Fe}(0)$ purity of $92 \%, \mathrm{Fe}(0)$ size of 30 mesh, $\mathrm{Fe}(0)$ quality of $30 \mathrm{mg} / \mathrm{L}$, $\mathrm{pH}$ of 6.0 , temperature of 25 and oscillation rate of $120 \mathrm{r} / \mathrm{min}$.The 5-day TCE removal rate of was $90.4 \%$, which testified that using $\mathrm{Fe}(0)$ to dispose TCE was feasible under the optimum conditions.

\section{Acknowledgments}

Funding of this project (No.51308274) supported by National Natural Science Foundation of China is greatly appreciated.

\section{References}

[1] Tie-hong Song, Yan-jiao Gao, Removal of trichloroethylene (TCE) from groundwater by GAC and ZVI, Desal. Water Treat.52(2014) 5990-5994.

[2]U.S. Environmental Protection Agency. 1998. June 24. 63 FR 34338.

[3] Franklin Obiri-Nyarko , S. Johana Grajales-Mesa , Grzegorz Malina ,An overview of permeable reactive barriers for in situ sustainable groundwater remediation, Chemosphere, 111 (2014) 243-259.

[4]Sweeny, K. H. , Reductive Treatment of Industrial Wastewaters. II Process Applications. AIChE Nat. Mtg, Boston, Portland, Chicago, 1980, 1981,1981.

[5] Gillham, R. W., O'Hannesin, S. F. ,Enhanced degradation of halogenated aliphatics by zero-valent iron. Groundwater, 32(1994) 958-967. 